\title{
STATISTICAL MODELLING OF PARTIAL CLAY COVER
}

\author{
Martin Hansen \\ Research geologist \\ Geological survey of Denmark and Greenland (GEUS) \\ Thoravej 8 \\ DK-2400 Copenhagen NV \\ e-mail mh@geus.dk
}

\section{INTRODUCTION}

One of the major controlling factors for groundwater recharge in area of partial clay cover is the distribution of the clay bodies. In order to evaluate the distribution of a partial clay cover in the Grundfør-Hinnerup area (Figure 1) and to quantify the probable distribution of the clay cover a series of statistical simulations of the clay distribution has been made. As conditioning data borehole data from the geological database PC ZEUS (Hansen, 1992) was used, and the simulations was done using sequential indicator simulation (Gómez-Hernandez \& Srivastava, 1990). For a more detailed description of the geology of this are see Gravesen 1997.

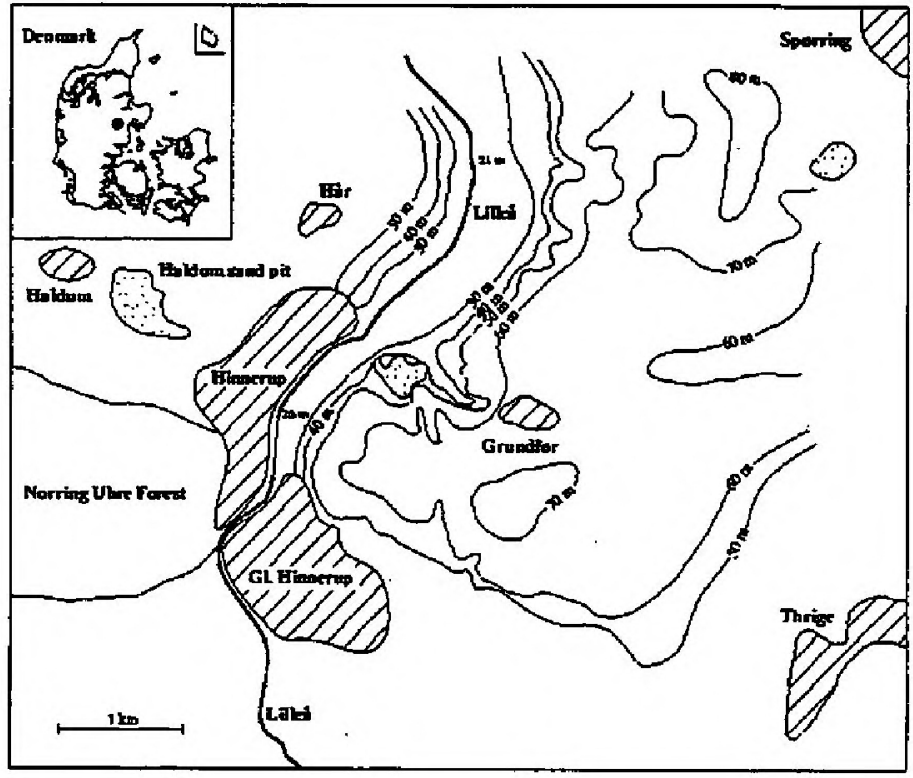

Figure 1: Location of the Grundfør - Hinnerup area.

To envision different degrees of protection of the underlying aquifers the simulations were made for three different minimum thickness of clay cover. For all the borings in the area coordinates and a Boolean value (that indicated whether or not the desired interval consists mainly of clay) extracted from the database. In the data extraction routine the geology were divided into two groups, one with hydraulic behaviour like sand and one like clay.

The results from the simulations are three probabilities maps showing the probabilities for having at least two, four or six metres of clay as the uppermost sediment. 


\section{DATA REQUIREMENTS}

The data needed for the simulations are $\mathrm{x}$ and $\mathrm{y}$ co-ordinates and a Boolean value (true or false) indicating whether the uppermost two, four or six metres of sediment consist mainly of clay. Besides the data a variogram (Isaaks \& Srivastava, 1989) describing the change in correlation with increasing distance between data points and the size of the fraction of borings that has the specified thickness of clay as the uppermost sediment is needed.

Data used for this modelling were borings from the PC ZEus (Hansen, 1992). The data extraction procedures disregard the soil layer and layers of postglacial sediments (which are of only minor importance in this area). Layers are grouped into two groups one group hawing a low hydraulic conductivity (clayey till, silty till, meltwater clay, meltwater silt and unspecified clay and silt) and one group with a higher hydraulic conductivity (meltwater sand, meltwater gravel and unspecified sand and gravel). In the following the two groups are referred to as clay and sand.

\section{MODELLING}

The simulations were done using ISIM3D (Gómez-Hernandez \& Srivastava, 1990) the variograms are fitted using PREVAR2D, VARIO2DP \& MODEL (Pannatier, 1993) and for visualising of the matrices the programme IMAGEX (Hansen, 1996) was used.

The dimensional models for the probability maps cover an area of $7 \mathrm{~km} * 6 \mathrm{~km}$ and the size of the regular grid are $280 * 240$ cells (total of 67,200 cells). The cell dimensions are 25 $m * 25 \mathrm{~m}$. For each of the three maps 50 simulations were made, the probability maps were then calculated at each cell unit by counting the number of cells with clay and the number without clay in all 50 matrices. If cell [1,1] has clay in 20 out of the 50 simulations, the probability of clay in this cell is $40 \%(100 * 20 / 50)$. Figure 2 shows the three probability maps and the position of the borings used in this analyse.

Doing a series of 50 simulations with different seed number for initiating the modelling routine gives 50 different realisations of the geological model. These different models all honour the hard well data and all show the same overall statistical distribution of the clay and sand layers. By combining a series of 50 simulations it is possible to calculate the areal (or spatial) probability for the presence of clay layers. These probability maps show where it is most likely that a clay cover of the specified thickness covers the reservoir. They also show where the description of the geology is most uncertain and in which area further collection of data will benefit most to the geological knowledge. As anticipated the size of the areas without clay cover decreases and the areas with high risk for absence of clay cover becomes more dominant with increasing demand on the thickness of the clay cover.

\section{DISCUSSION}

One of the major problems with this type of modelling is the lack of statistical data on the restricted Quaternary layers. Due to the small size of these layers compared to the distance between the borings it is often impossible to collect the data needed to establish a proper variogram from well information alone.

As the data for this analyse was based on existing data the distribution of the borings is far from optimal as can be seen in Figure 2D. The borings in this area is a mixture of water supply borings and geotechnical borings. The water supply borings are located in areas where water is needed while the geotechnical borings on this map are located mainly along a highway in the eastern part of the area. For this reasons there is a lack of data in the south-western part where Norring Uhre forest is located while the data density is very high en the eastern part along the highway. 

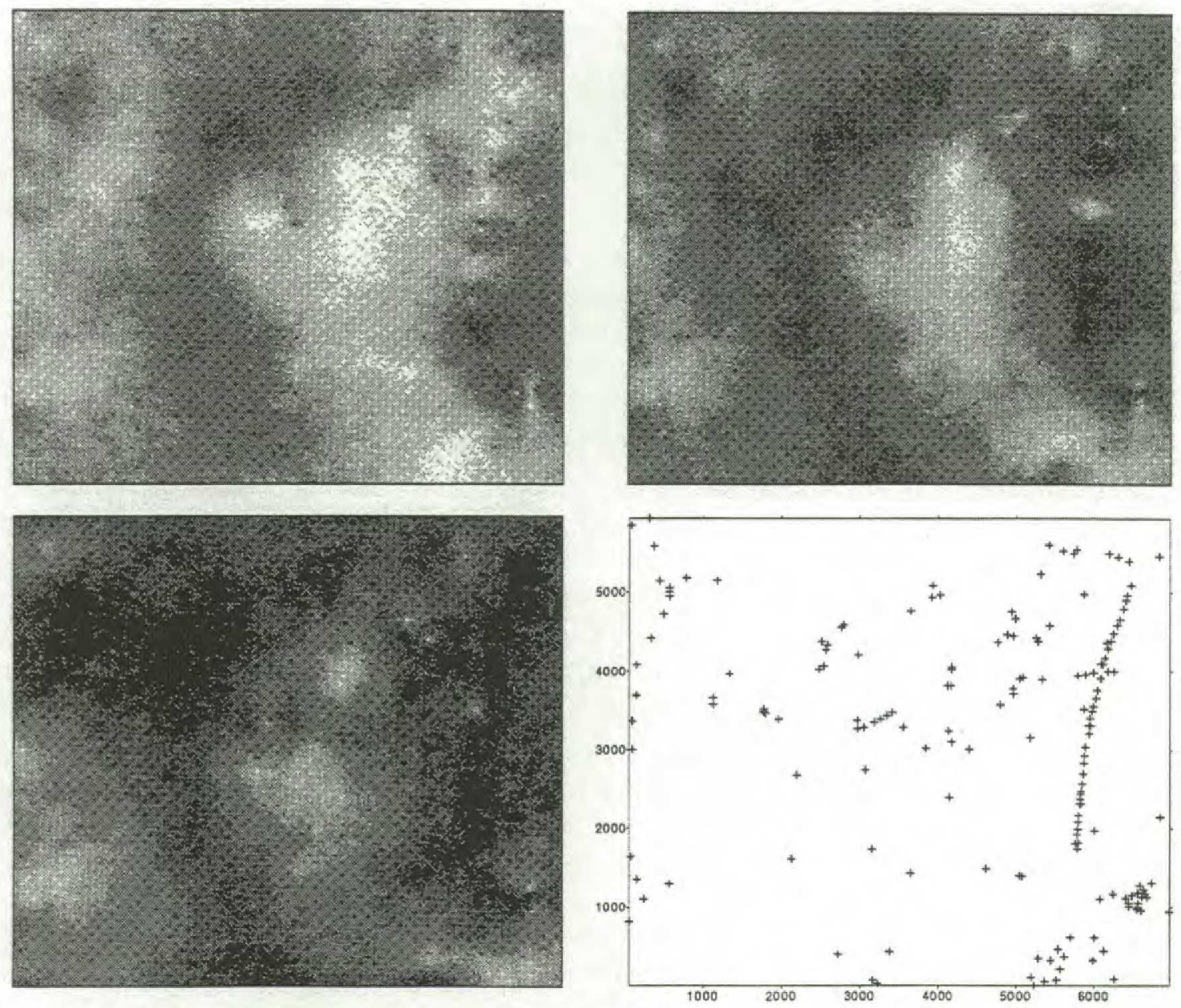

Figure 2: Three probability maps showing the probability for having at least two (A; top left), four (B; top right) or six (C; bottom left) metres of clay as the uppermost sediment. The light grey regions show areas in with there is high possibility of clay cover and the dark regions shows areas with high risk for absent clay cover. (D; bottom right) Shows the distribution of borings used for this analyse. The scale is in metres.

In order to compensate for this inhomogeneous distribution of data the model can be improved by adding other types of data. This could be field measurements of the size, orientation and spatial distribution of these layers or geoelectrical data.

\section{INCOORPERATION OF GEOELECTRICAL DATA}

The Grundfør - Hinnerup area has been used as a test area for the Danish Strategical Environmental Research Programme and is as a part of this project heavily investigated by Pull Array Continuos Electrical Profiling (PACEP) (Christensen \& Sørensen, 1994).

In order to use the two different types of data in one statistical model is necessary to have a correlation between the two data sets. In this example the geological description can is simplified to sand or clay. The geological data can be represented using $\mathrm{x}, \mathrm{y}$ co-ordinates and a Boolean value indicating whether the geology at the co-ordinate is clay or not. On the other hand the geoelectrical measurements is a continuo span that must be represented as $\mathrm{x}$ and $\mathrm{y}$ co-ordinates and a real number giving the resistively for the geology at the co-ordinates. The correlation factor is not easily retrieved and the possible values for sand overlay the possible values for clay. If a correlation between the two data sets can be established for example from geoelectrical borehole logging or by the averaging the geology represented by a geoelectrical measurement. It would be possible to generate a statistical model that combines the two dif- 
ferent types of data by using the co-Kriging or co-simulation programmes in the GSLIB package.

\section{CONCLUSIONS}

Statistical modelling is not yet a common tool for generating input to hydrological modelling it is however a powerful toll to calculate and quantify different themes for the hydrogeological modelling. This could be probabilities maps like the ones presented in this paper and used for distribution of the groundwater recharge or any other question other question that can be answered by a yes or a no (the simpler the question the smaller demand for data).

The lack of data within the correlation length of the geological units / classes is another problem and often it is not possible establish a proper variogram. This situation could be changed by adding data from field measurements of the size, orientation and spatial distribution of these layers or by adding geoelectrical data if present.

If the purpose of the modelling is transport of pollutants then the distribution of the transport controlling layers then the average distribution of the clay layer layers is insufficient. In this case it is necessary to have a bet (or several bets as in the case of stochastic modelling) on the actual distribution of the clay layers. An example of this is demonstrated by Henriksen et. al 1996. The hydrological modelling must then be performed on all the possible distribution or on some of the models ranked according to a significant hydraulic criterion. This could be the connectivity of flow controlling layers (high or low permeability layers).

\section{REFERENCES}

Christensen, N. B. \& Sørensen, K. I. (1994) Integrated use of electromagnetic methods for hydrogeological investigations. Proceedings of the symposium on the Application of Geophysics to Engineering and Environmental Problems, Boston, USA, pp. 163-176.

Clayton, V. D. \& Journel A. G. (1992) GSLIB: Geostatistical Software Library and User's Guide. Oxford University Press. ISBN 0-19-507392-4. 340 p..

Gómez-Hernandez, J. \& Srivastava, R. M. (1990) ISIM3D: An ANSI-C three dimensional multiple indicator conditional simulation program. Computers \& Geosciences, 16(4) pp. 395-440.

Gravesen, P. (1997) Three-dimensional Geological Model of the Complex Aquifers in an Incised Quaternary Valley in Jylland, Denmark. EEGS European Section, $3^{\text {rd }}$ meeting, Environmental and Engineering Geophysics (this volume).

Hansen, M. (1992) PC Zeus; Vejledning $i$ anvendelse af PC Zeus. Danm. Geol. Unders. (in Danish), 90 p..

Hansen, M. (1995) IMAGEX; A PC programme for visualizing large 3-dimensional matrices (up to $1 \hat{\sigma}^{7}$ cells). Submitted to Computers \& Geosciences in July 1995.

Henriksen, H., J., Hansen, M. \& Dahlstrøm, K. 1996: Hydrological data worth associated with implementation of groundwater protection zones. Nordic Hydrological Conference 1996 volume 1 , p. $36-45$.

Isaaks, H. E. \& Srivastava, M. R. (1989) An Introduction to Applied Geostastitics. Oxford University Press, Inc. ISBN 0-12-208916-2. 440 p..

Pannatier, Y. (1993) PREVAR2D, VARIO2DP, \& MODEL: Three PC programs for 2dimensional variograms modelling. Institute of Mineralogy, University of Lausanne, BFSH 2, 1015 Lausanne, Switzerland, E-Mail: Yvan.Pannatier@imp.unil.ch. 